\title{
The Education of Japanese Honorifics and Cultivating Intercultural Communication Competence
}

\author{
Jinxin Liu* \\ Dalian Jiaotong University, Dalian 116028, Liaoning Province, China
}

\begin{abstract}
Japanese honorifics which symbolizes the social culture of Japan are linguistic forms that are indispensable in the Japanese language education. Hence, the Japanese language education requires an improvement of previously solidified teaching methods with the cultivation of students' intercultural communication competence, in order for students to understand Japanese honorifics in-depth and apply them in practice. This paper analyzes the necessity of cultivating students' intercultural communication competence, the difficulties in Japanese honorifics education, and proposes specific training methods to help students improve their competence.
\end{abstract}

Keywords: Intercultural communication competence; Japanese honorifics; Training methods

Publication date: May, 2021; Publication online: 31 May, 2021

*Corresponding author: Jinxin Liu, Liujinxin2007ok@163.com

\section{Introduction}

Japanese honorifics are important in Japanese language education; however, it is a difficult subject. The development of this subject may encourage students to have a better understanding of Japanese social psychology, communication habits, and way of thinking. In order to achieve effective language education, teachers should emphasize on cultivating students' intercultural communication competence and make appropriate reforms in teaching Japanese honorifics.

\section{Necessity of Cultivating Students'} Intercultural Communication Competence in Japanese Honorific Education

Language is a tool often used in human communication. Each country has its own unique language and culture. Although China and Japan are neighboring countries and they are in the same cultural sphere which is heavily influenced by Chinese characters, there are still barriers in communication. Their social culture, mentality, and values are different. From the perspective of our country's social culture, it is difficult to communicate smoothly with Japanese people without any grammatical errors. A few schools are influenced by the traditional language teaching model, hence, neglecting cultural factors (See Table 1).

Due to many shortcomings in Japanese honorifics education, students' intercultural communication competence has been severely hindered. Hence, students experience communication barriers when they are unable to openly use these honorifics when communicating with Japanese people. Therefore, it is necessary for teachers to cultivate students' intercultural communication competence.

\section{Difficulties in Teaching Japanese Honorifics} In 2007, the Cultural Affairs of Japan made modifications to the traditional classification of Japanese honorifics. In the past, Japanese honorifics have three categories: honorifics, modest words and Teineigo. After these changes, there are five major categories, including refined 
words, modest words I and II (from the previous modest words category) in addition to honorifics and Teineigo. The modified classification of Japanese honorifics is shown in Table 2.

Table 1. Deficiencies in Japanese honorific education

\begin{tabular}{|l|l|}
\hline \multicolumn{1}{|c|}{ Deficiencies } & \multicolumn{1}{c|}{ Explanation } \\
\hline Teaching materials & $\begin{array}{l}\text { The teaching materials used in Japanese honorifics courses have no specific modules to explain } \\
\text { these honorifics in-depth. Hence, only very little insights to the Japanese social culture, mentality } \\
\text { and values are emphasized. }\end{array}$ \\
\hline Teachers & $\begin{array}{l}\text { 1. While conducting Japanese honorifics lessons, teachers usually intersperse them with } \\
\text { explanations regarding the Japanese language, however, the contents are only limited to the ones } \\
\text { in textbooks and teachers seldom carry out any extra activities. } \\
\text { 2. The explanations on social cultures, mentality and values of the Japanese are insufficient, } \\
\text { resulting in a superficial understanding of honorifics. Students are not clear on where and with } \\
\text { whom these honorifics should be used. }\end{array}$ \\
\hline
\end{tabular}

Table 2. Classification of Japanese honorifics

\begin{tabular}{|c|l|}
\hline Categories & \multicolumn{1}{c|}{ Explanation } \\
\hline Honorifics & $\begin{array}{l}\text { The subjects are usually the second or the third person. It expresses the respect that the speaker } \\
\text { has towards the narrated subject, such as, the elderly, guests, and those of higher status. }\end{array}$ \\
\hline Modest words & $\begin{array}{l}\text { To reflect the status of the listener or the subject, the speaker lowers his or her status or the } \\
\text { subjects'. }\end{array}$ \\
\hline Teineigo & $\begin{array}{l}\text { It is merely an expression of respect of the speaker towards the listener and has no relationship } \\
\text { with the subject. It is generally used at the end of a sentence. }\end{array}$ \\
\hline Refined words & $\begin{array}{l}\text { The speaker deliberately modifies or "beautifies" their words to add refinement in their speech. } \\
\text { These words are generally used by women. }\end{array}$ \\
\hline
\end{tabular}

There are issues in teaching Japanese honorifics because of the complexity in classification, as well as the social and cultural background of the Japanese. When students begin to learn Japanese honorifics, it is understood that honorifics are used to convey respect. ${ }^{[1]}$ In fact, this view is very general. Japanese honorifics can also be used to express the closeness in relationships, benevolence, and a person's status. To use Japanese honorifics openly, learning the cultural factors behind Japanese honorifics is crucial compared to just understanding its' grammar.

\section{Effective Methods to Cultivate Students' Intercultural Communication Competence in Japanese Honorifics Education}

Teachers need to reinforce the understanding of cultural factors in order to effectively cultivate students' intercultural communication competence in the education of Japanese honorifics. If teachers only introduce briefly the social and cultural aspects, it is often difficult for students to truly grasp the concept. Hence, creating actual scenes to explain grammatical sentence and organizing consolidation training for students in these situations improves their understanding and intercultural communication competence while mastering this subject.

\subsection{Educating on the occasions to use honorifics} The occasions for using Japanese honorifics are shown in Table 3. 
Table 3. Occasions to use Japanese honorifics

\begin{tabular}{|c|l|}
\hline Occasions & \multicolumn{1}{c|}{ Explanation } \\
\hline Service industries & $\begin{array}{l}\text { Honorifics are used when engaging in service-oriented industries. For example, restaurant } \\
\text { waiters, doctors, and lawyers are required to use honorifics when communicating with their } \\
\text { customers. }\end{array}$ \\
\hline Workplace & $\begin{array}{l}\text { Honorifics are used when subordinates speak to their superiors, junior staffs to their seniors, and } \\
\text { during business occasions among personnel from different companies. }\end{array}$ \\
\hline Formal occasions & High-level honorifics are required in speeches, receptions and other formal occasions. \\
\hline
\end{tabular}

When teachers explain the use of Japanese honorifics via simulated scenarios, it enhances students' learning experiences and heightens their understanding during conversations in various situations. ${ }^{[2]}$ For example, in convenience stores and workplace scenarios, whereby students roleplay and hold conversations as cashiers, consumers, subordinates and superiors. Hence, this simulation will not only leave lasting impressions on students, but also cultivate their intercultural communication competence.

\subsection{Educating on Japanese honorifics speakers}

From the perspective of Japanese language speakers, honorifics are mainly used when communicating with seniors or the elderly. ${ }^{[3]}$ In addition to that, speakers can distinguish the degree of respect based on their status. During lessons, teachers can use the example of describing meals for staffs of different ranking in a company. Although it is the same subject of dining, distinctive expressions are used based on different levels of respect in regard to their ranks. In Japanese companies, the ranks are in the order of the president, director, and section chief. By learning this, students can accurately grasp the speakers' status via Japanese honorifics, and hence, improving the students' intercultural communication competence.

\subsection{Educating on the psychology of interpersonal communication}

When cultivating students' intercultural communication competence in the education of Japanese honorifics, emphasis should be on explaining the psychology of interpersonal communication. The use of Japanese honorifics may reflect the psychological distance between the speaker and the listener or subject. ${ }^{[4]}$ Explaining the psychology aspect is important but a difficult topic in Japanese honorific education. When communicating with people of the same social status as oneself, the use of Japanese honorifics indicates the psychological distance and relationship between the speaker and the listener. For example, in a workplace, two colleagues who are familiar with each other do not usually use honorifics in their conversation. However, when these two colleagues unexpectedly use honorifics with each other, they need to consider whether there are problems in their relationship which had caused either of them to feel uncomfortable. In some cases, the use of Japanese honorifics may incur the listener to feel disrespected or left out.

\section{Conclusion}

In summary, while the education of Japanese honorifics emphasizes on the social and cultural background, it also needs to cultivate students' intercultural communication competence through simulations and role-playing scenarios. This is to encourage students to use Japanese honorifics more accurately and openly, hence, achieving barrierfree communications.

\section{Disclosure statement}

No conflict of interests.

\section{References}

[1] Li, X(2021). The construction of a diversified Japanese "appropriate expression" awareness training model from the perspective of "Internet +". Knowledge Window (Teacher Edition), (02): 52-53. 
[2] Jing, Y(2019). Research on the introduction of cross-cultural communication concepts into publicly selected foreign language teaching-Taking Japanese honorific teaching as an example. Media Forum, 2(23): 79, 81.

[3] Yi, H(2019). Analysis of the specific use of selfhumility and respect in Japanese teaching as a second foreign language in university. Modern Communication, (19): 19-20.

[4] Sa Y(2018). A probe into the Japanese honorific teaching method-combined with the "can-do" mode in the JF Japanese Standard. Education Teaching Forum, (16): 213-215. 